\title{
MANEJOS CONSERVACIONISTAS EM SOLO ARENOSO PARA O PLANTIO DE AMENDOIM NA REFORMA DE CANA-DE-AÇÚCAR
}

\author{
Denizart Bolonhezi ${ }^{1}$, André Samir Uchelli ${ }^{2}$, Renan Freire Bottignon ${ }^{3}$, Olavo Betiol ${ }^{4}$, Natã Fernandes \\ Bonatto Pantolfi ${ }^{5}$ e José Renato Franzoi Trevizan ${ }^{6}$
}

\begin{abstract}
${ }^{1}$ Pesquisador Científico do IAC, Centro Avançado de Pesquisa em Cana, Ribeirão Preto, SP; ${ }^{2}$ Graduando em Agronomia, UNIFAI- Centro Universitário de Adamantina, Adamantina,SP; ${ }^{3}$ Eng. Agr. na Cooperativa CASUL, Rinópolis, SP; ${ }^{4}$ Pós-graduando (Ciência do Solo) da FCAV/UNESP, Jaboticabal, SP; ${ }^{5}$ Graduando em Agronomia, UNIFAI- Centro Universitário de Adamantina, Adamantina,SP; ${ }^{6}$ Eng. Agr. na Cooperativa CASUL, Rinópolis, SP.
\end{abstract}

RESUMO: O presente estudo teve como objetivo quantificar a produtividade de vagens do amendoim submetido a três manejos de solo na reforma de cana crua, bem como medir os teores de aflatoxina e impurezas nas amostras. O experimento foi conduzido em solo arenoso, localizado na cidade de Iacri/SP, utilizando-se delineamento em blocos casualizados com 9 repetições. Os tratamentos foram constituídos por três manejos de solo (preparo convencional, cultivo mínimo em faixa com Rip Strip ${ }^{\circledR}$ e semeadura direta). Considerando as condições experimentais e ocorrência de déficit hídrico na fase reprodutiva, não houve diferença estatística entre os tratamentos quanto ao estande de plantas, número de vagens por planta, produtividade de vagens, $\%$ de impurezas e níveis de aflatoxina nos grãos. Palavras-Chave: semeadura direta, Rip Strip ${ }^{\circledR}$, textura arenosa, produtividade e aflatoxina.

\section{INTRODUÇÃO}

A área em cultivo de amendoim no estado de São Paulo aumentou 60\% nos últimos 10 anos, atingindo 136 mil ha na safra 2018/19, dos quais mais de $65 \%$ estão em reforma de canaviais (CONAB, 2019). BRAGA et al. (2018) verificaram através de questionários aplicados a usinas e associações de fornecedores de cana, que na safra 2018/19 o amendoim foi cultivado em $11 \%$ dos 412 mil ha destinados a reforma, dos quais 13 mil ha foram em sistema de meiosi. Todavia, a parceria entre as cadeias produtivas do amendoim e da cana-de-açúcar tem sido prejudicadas devido aos recorrentes problemas com erosão hídrica ocorridos no período de reforma.

Embora a semeadura direta de amendoim já tenha sido objeto de pesquisa desde o final dos anos 90, estudos sobre a produção de amendoim na palha ainda são incipientes, sobretudo com relação à viabilidade do preparo reduzido em faixa, com Rip Strip. Para as condições de reforma de canaviais, resultados preliminares do projeto financiado pelo CNPq e Fundação Agrisus, denominado 


\section{Encontro Sobre a Cultura do Amendoim \\ 15 a 17 de agosto de 2019 na Estação de Eventos Cora Coralina e FCAV/UNESP, Jaboticabal-SP}

"Amendoim na Palha", concluíram que em solo argiloso a produtividade foi três vezes menor na semeadura direta e o percentual de impureza e teor de aflatoxina foram superiores nos manejos conservacionistas (BOLONHEZI et al., 2017).

Considerando o contexto, o presente trabalho teve como objetivos; avaliar as características agronômicas e nível de aflatoxina, em amendoim cultivado em três manejos (preparo convencional, preparo reduzido em faixa com Rip $_{\text {Strip }}{ }^{\circledR}$ e semeadura direta) na reforma de cana crua cultivada em solo arenoso.

\section{MATERIAL E MÉTODOS}

O ensaio realizado no campo foi instalado em uma área de cana-de-açúcar com o histórico de cinco cortes mecanizados e sem queima (14,5 mg.ha ${ }^{-1}$ de matéria seca de palhiço de cana), na cidade Iacri/SP. O solo da área é classificado como Argissolo Vermelho Amarelo, textura arenosa. O experimento foi instalado em blocos casualizados com três tratamentos de manejo de solo (convencional, preparo reduzido e plantio direto), em nove repetições. Cada parcela possuía as seguintes dimensões: $10,8 \mathrm{~m}$ x $70 \mathrm{~m}$.

O manejo do solo foi realizado no dia 05/11/2018. A cultivar Granoleico foi semeada no dia 21/11/2018 diretamente no tratamento semeadura direta, utilizando-se uma semeadora pneumática (Jumil ${ }^{\circledR}$, Guerra GII). A mesma semeadora foi utilizada no tratamento convencional, que consistiu da passagem de grade intermediária, seguida por gradagem aradora, novamente uma gradagem intermediária e finalizado com uma gradagem niveladora. $\mathrm{O}$ tratamento denominado preparo reduzido em faixa, foi realizado com equipamento de quatro hastes, denominado Rip Strip ${ }^{\circledR}$ (BM Dumont). Baseado nos resultados das análises químicas e de granulometria (Tabela 1 e 2), foram calculadas as quantidades de calcário e fertilizantes aplicados. Foram aplicados $248 \mathrm{~kg} \mathrm{ha}^{-1}$ do fertilizante Top Phos $280 \mathrm{HP}$, quantidade que forneceu 8, 160, 25 e $12 \mathrm{~kg} \mathrm{ha}^{-1}$ de $\mathrm{N}, \mathrm{P}_{2} \mathrm{O}_{2}$, Ca e S, respectivamente.

Tabela 1. Resultados nas análises químicas da fertilidade do solo na área de condução da pesquisa, referente à camada de 0-20 $\mathrm{cm}$ de profundidade. Iacri, SP, 2018.

\begin{tabular}{|c|c|c|c|c|c|c|c|c|c|}
\hline M.O. & $\mathrm{P}$ & $\mathrm{pH}$ & $\mathrm{K}$ & $\mathrm{Ca}$ & $\mathrm{Mg}$ & $\mathrm{H}+\mathrm{Al}$ & SB & CTC & V \\
\hline $\mathrm{g} \mathrm{dm}^{-3}$ & $\mathrm{mg} \mathrm{dm}^{-3}$ & & & - & $--\mathrm{mr}$ & $\mathrm{dm}^{-3}-$ & ----1 & ------ & $\%$ \\
\hline 11 & 11 & 4.9 & 2.3 & 11 & 5 & 19 & 18.3 & 37.3 & 49.1 \\
\hline
\end{tabular}

Tabela 2. Resultados da análise granulométrica do solo na área de condução da pesquisa, referente à camada de 0-20 cm de profundidade. Iacri, SP, 2018.

\begin{tabular}{|c|c|c|c|c|}
\hline Argila & Silte & Areia Fina & Areia Grossa & Areia Total \\
\hline \multicolumn{5}{|c|}{ - } \\
\hline 61 & 28 & 746 & 166 & 912 \\
\hline
\end{tabular}




\section{Encontro Sobre a Cultura do Amendoim \\ 15 a 17 de agosto de 2019 na Estação de Eventos Cora Coralina e FCAV/UNESP, Jaboticabal-SP}

As amostragens de plantas foram realizadas nos meses de dezembro, janeiro e março, nas quais foram coletadas plantas em 1,0 m de linha de semeadura. Foram mensurados o estande e número de estruturas reprodutivas, após isso, foram secas para determinação da biomassa seca da parte vegetativa. A colheita foi realizada no dia 04/04/2019, quando a maioria das vagens encontravam-se no estádio R8. A colheita foi realizada de duas maneiras, área total e amostras trilhadas com trilhadoras experimentais. Considerou-se para trilhar as amostras, três pontos de $5 \mathrm{~m}$ em diferentes leiras. As vagens foram armazenadas para posterior limpeza e determinação das pesagens. Em seguida o restante da parcela (seis leiras de 70 metros) foram colhidas com uma recolhedora (Twin Master, Colombo/Miac ®). A produção foi transferida para um transbordo, o qual foi pesado sobre "balança de sapata" com capacidade para 10 mil kg e resolução de 200 gramas. Após pesagem, foi retirada uma amostra de amendoim de $25 \mathrm{~kg}$ de cada parcela, para posterior beneficiamento e determinação do teor de umidade, do percentual de impureza, rendimento de grãos e nível de aflatoxina. Os resultados foram submetidos à análise de variância e as médias comparadas pelo teste de Tukey (5\%), utilizando o software estatístico AgroEstat (BARBOSA \& MALDONADO, 2015).

\section{RESULTADOS E DISCUSSÃO}

Inicialmente é importante mencionar que os dois veranicos ocorridos durante a safra (dezembro e janeiro), contribuiu para reduzir em $23 \%$ a média da produtividade de amendoim na região de condução da pesquisa, em comparação com a safra 2017/18.

Não houve diferença significativa quanto ao estande final de plantas, média de 23,5 plantas por metro (Figura 1 - A). A falha no estande e estabelecimento inicial, tem sido apresentado como um dos motivos da menor produtividade do amendoim em manejos conservacionistas de solo na reforma de canaviais (BOLONHEZI et al., 2018).

Na avaliação realizada aos 60 dias após a semeadura, após os dois períodos de veranicos, o tratamento Rip Strip diferiu estatisticamente quanto número de estruturas reprodutivas contabilizadas em 1 metro (Figura 1 - B). A mesma avaliação aos 100 dias e na pré-colheita não apresentou diferença entre os tratamentos para a variável número de estruturas reprodutivas. AMBROSIO et al. (2016), estudando esses mesmos manejos, para as condições de Assis/SP e Novo Horizonte/SP, para os genótipos IAC-OL3 e IAC-503, respectivamente, também não verificaram diferenças estatísticas quanto ao número de estruturas reprodutivas. 
XVI Encontro Sobre a Cultura do Amendoim

15 a 17 de agosto de 2019 na Estação de Eventos Cora Coralina e FCAV/UNESP, Jaboticabal-SP
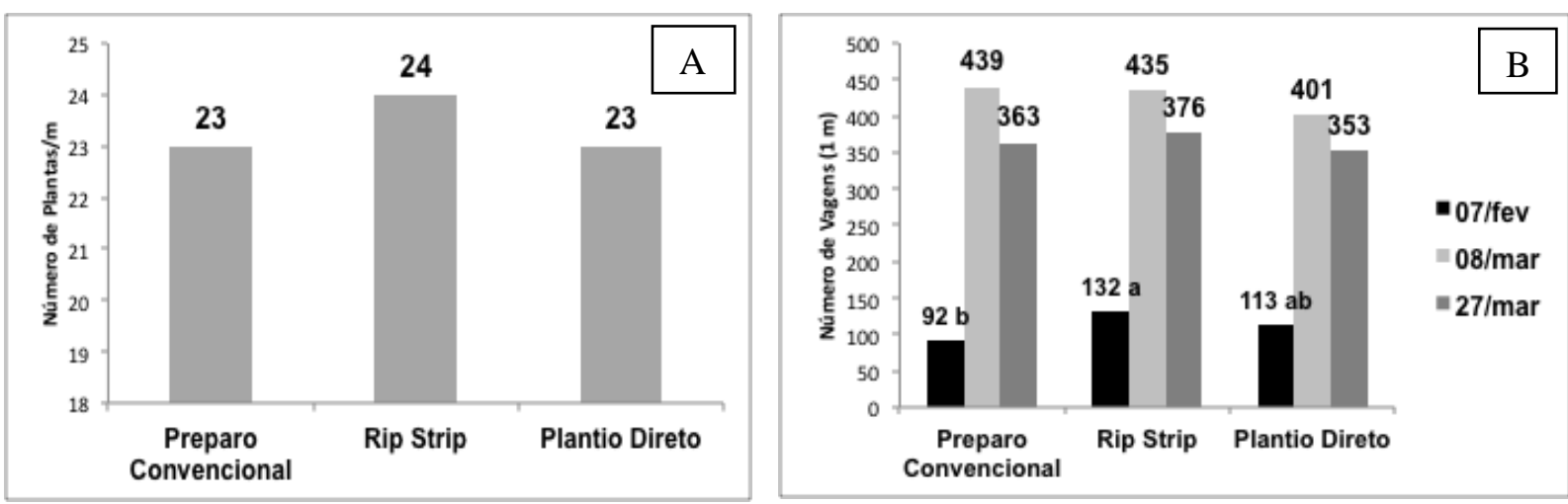

Figura 1. Estande final de plantas (A) e número de vagens em um metro de linha (B). Iacri, SP.

Os resultados de produtividade de vagens estão apresentados na Figura 2. Observa-se que a produtividade aferida na área total, sem a correção do teor de umidade e porcentagem de impureza, apresentou diferença estatística entre os tratamentos, variando entre 15 e 22 sacas a mais por hectare na semeadura direta. Todavia, após padronização das amostras, não houve diferença estatística.

Para as amostras trilhadas com trilhadora de parcelas experimentais, o mesmo resultado foi observado. Este resultado é promissor, visto que, são manejos que apresentam menores custos de produção e ajudam no controle da erosão hídrica. Resultados similares também foram encontrados em pesquisas conduzidas por outros autores em solos arenosos (AMBROSIO et al., 2016; BOLONHEZI et al., 2018).
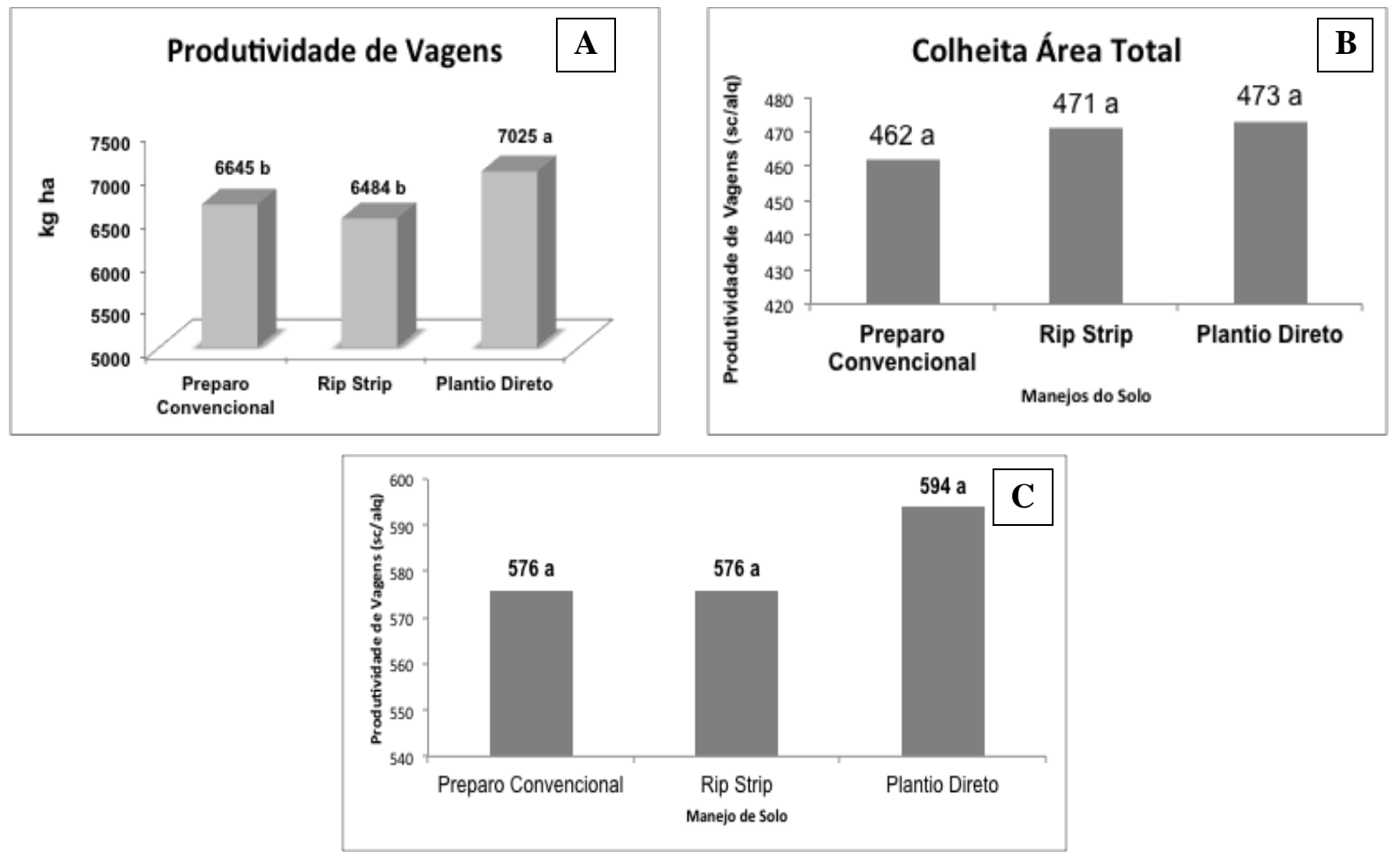

Figura 2. Produtividade de vagens do cv. Granoleico, submetido a diferentes manejos de solo na reforma de cana crua: (A) Colheita da parcela integral sem desconto das impurezas; (B) Colheita da 


\section{Encontro Sobre a Cultura do Amendoim \\ 15 a 17 de agosto de 2019 na Estação de Eventos Cora Coralina e FCAV/UNESP, Jaboticabal-SP}

área total com desconto de impurezas e umidade; (C) Colheita com trilhadora de parcelas. Iaci/SP, 2019.

Quanto aos aspectos relacionados à qualidade, verifica-se que os manejos conservacionistas apresentaram em média 1,2\% menos de impureza em comparação ao preparo convencional (Figura 3). É importante salientar que essa medida somente é possível quando se realiza o recolhimento em escala comercial, ou seja, com a recolhedora utilizada pelo produtor. Da mesma forma, ocorre com a determinação dos níveis de aflatoxina, a qual ficou muito acima dos níveis aceitáveis em todos os tratamentos e sem diferença estatística, provavelmente devido ao alto coeficiente de variação (Figura 3). Na safra 2017/18, LEAL et al. (2018) verificaram menores níveis de aflatoxina no tratamento semeadura direta, evidenciando a necessidade de mais pesquisas relacionadas ao tema.
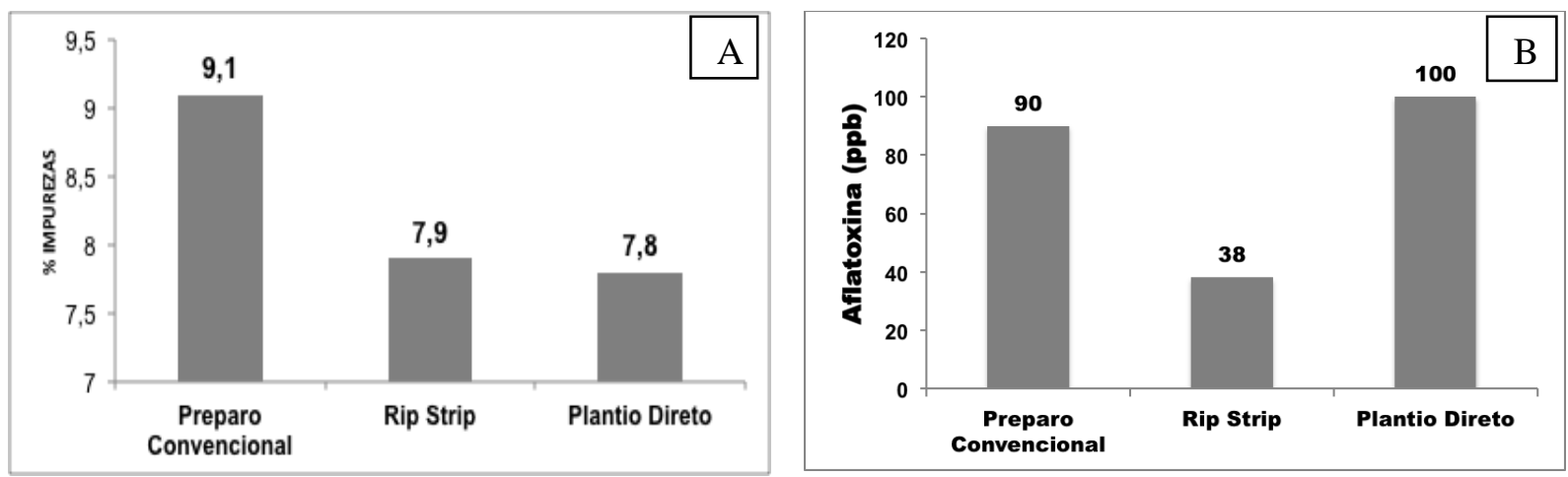

Figura 3. Porcentagem de impurezas (A) e teor de aflatoxina (B) no cv. Granoleico, submetido a diferentes manejos de solo na reforma de canaviais. Iacri/SP, 2019.

\section{CONCLUSÕES}

Em condições de solo arenoso e ocorrência de deficiência hídrica na fase reprodutiva do amendoim, a semeadura direta apresenta potencial de ganhos médios de $4 \%$ na produtividade de vagens, em comparação com o preparo convencional. Com relação aos aspectos de qualidade, os manejos conservacionistas apresentaram menor percentual de impurezas e sem diferenças quanto aos níveis de aflatoxina.

\section{AGRADECIMENTOS}

Ao Conselho Nacional de Desenvolvimento Científico e Tecnológico (CNPq), pela bolsa de Desenvolvimento e Inovação Tecnológica (DT-2), processo 311121/2015-2. Os autores agradecem ao apoio financeiro fornecido pela Cooperativa CASUL e por toda infraestrutura disponibilizada pela Bonato Pantolfi. 


\section{Encontro Sobre a Cultura do Amendoim \\ 15 a 17 de agosto de 2019 na Estação de Eventos Cora Coralina e FCAV/UNESP, Jaboticabal-SP}

\section{REFERENCIAS BIBLIOGRÁFICAS}

AMBROSIO, L.M.S.; BOLONHEZI, D.; BARINI, R.T.; BETIOL, V.; GONÇALVES, L.H.de O.; LEAL, E.R.P.; SCARPELLINI, J.R. Análise de Crescimento de Cultivares de Amendoim em Diferentes Sistemas de Manejo do Solo na Palhada de Cana Crua. In: WORKSHOP AGROENERGIA, XI, Ribeirão Preto. Anais... Instituto Agronômico, Centro de Cana-de-Açúcar, Ribeirão Preto, 2017. [Cd-Rom].

BOLONHEZI. D.; AMBROSIO, L.M.S.; BARINI, R.T.; BETIOL, V.; GONÇALVES, L.H.O.; SCARPELLINI, J.R.; BOLONHEZI, A.C. Peanut pod yield and soil compaction in Brazilian conservation agriculture system. VII, WORLD CONGRESS ON CONSERVATION AGRICULTURE, Rosário, Argentina, 2017, Proceedings...Associacion Argentina de Productores en Siembra Directa (AAPRESID), Federação Brasileira de Plantio Direto na Palha (FEBRAPDP), Rosário, Argentina, 2017, p. 72-75. < http://proceedingswcca.worldpress.com/ > Disponível em 15/06/2018.

BRAGA JUNIOR, R.L.do C.; LANDELL, M.G.A.; SILVA, D.N.da; BIDÓIA, M.A.P.; SILVA, T.N.; THOMAZINHO JÚNIOR, J.R.; SILVA, V.H. P.; ANJOS, I.A. dos. Censo Varietal IAC de Canade-Açúcar no Brasil (Safra 2017/18) e na Região Centro-Sul (Safra 2018/19). Campinas, Instituto Agronômico, 2019, 64 p. (Boletim Técnico IAC, n. 221)

CONAB. Amendoim total ( $\mathbf{1}^{\mathrm{a}}$ e $\mathbf{2}^{\mathrm{a}}$ safra) - Brasil: série histórica de área plantada. Disponível em:< http://conab.gov.br/OlalaCMS/uploads/arquivos/. Acesso em 10 agosto 2015.

LEAL, E.R.P.; UCHELI, A.S.; BETIOL, O.; AMBROSIO, L.M.S.; BETIOL, V.; BOLONHEZI, D. Produtividade e aflatoxina em amendoim cultivado em sistemas conservacionistas de manejo do solo na reforma de cana crua. In: ENCONTRO DE AMENDOIM, XV, Resumos... FCAVJ/UNESP, Jaboticabal, 2018, p. 179-184. 